Moon, D. Steele, L.R.C.S.Edin., appointed Lecturer in Clinical Surgery at University College, Dundee.

PARry. Thomas Llewelyn. appointed Assistant Medical Officer to the West Derby Union, Walton-on-the-Hill, Liverpool, vice F. T. Jacks Jn, resigned.

Rorie, James, M.D., Medical Superintendent Lundee Royal Ass]um, appointed Clinical Lecturer in Mental Diseases at Univer:siy College, Dundee.

ScotT, A. W. M.D.Brux., M.R.C.S., T.S.A., appointed Medical Offeer for the Handsworth District of the sheffield tnion.

Tomlinson, H. E., appointed House-Physician to the General Infirmary, Leeds.

WaLSH, Leslie A., M.R.C.S., L.R.C.P., I.S.A., anpointed House-Surgeon to the Royal United Hospital, Batli, rice Mr. F. Lace.

Wellington, R. Henslowe, L.R.C.P., M.R.C.S., appointed Medical Officer of Health to the Wisbech Port and Port Hospital; Medical Officer of Health to Sutton Bridge; Medical Officer and Public Vaccinator to the Sutton Bridge District of the Holbeach Union; and Admiralty Surgeon and Agent at Sutton Bridge.

WiLletT, George G. Drake, M.R.C.S., reappointed Medical Officer to the Bilton and Marksbury District of the Keynsham Union.

Woodforde, -, M. D., appointed Medical Officer of Health for the Eorough of Maidenhead for a term of five years.

ERRATA.-The following appointments were recently made at the Royal Infirmary, Manchester, and not at the Monsall Fever Hospital, as given in the BRITISH MEDICAL JOURNAL of September 12th:-HousePhysicians: Edward Mansfield Brockbank, M.B., Ch. B.Vict.; and W.
B. Warrington, M. B., Cl. B.Vict. House-Surgeons: William J. HowB. Warrington, M. B., Ch. B.Vict. House-Surgeons: William J. How-
arth, M. B., Ch.B.Vict.; Richard Clegg, M.R.C.S.Eng., L.R.C.P.Lond. T. W. Iddon, M.B., C.M.Edin., M.K.C.S.Eng.; and Albert Edward Berry, M.B.Lond., M.R.C.S.Eng., L.R.C.P.Lond.

\section{BIRTHS, MARRIAGES, AND DEATHS.}

The charge for inserting announcements of Births, Marriages, and Deaths is ss. 6d., which sum should be forwarded in Post Office Order or Stamps with the notice not later than Wednesday morning, in order to insure inscrtion in the current issue.

\section{BIRTHS.}

A clison.-At Fuller House, Kettering, North Hants, on September 14th, the wife of Joln Allison, M.B., C.M.Edin., of a daughter.

Coventon.-At "Indore," Pevensey Road West, St. Leonards, on September 4th, the wife of Charles "Arthur Coventon, M.R.C.S., L. R.C.P., of a daughter, "Vera Mary."

Clark.-On Sunday, September 13th, at 78 , Church street, Lancaster, the wife of Robert Clark, L.R.C.P.Edin., of a daughter.

Ferguson.-At Cutch Bhuj, India, on August 2:3rd, the wife of SurgeonMajor J. E. Ferguson, I.M.S., of a son.

Lmont.-On September 6th, at 3, Queen's Square, Newcastle-on-Tyne, the wife of James Limont, M.B., of a daughter.

PAterson.-At 41, Seafield Road, Dundee, on September 9 th, the wife of A. M. Paterson, M.D., of a son.

\section{MARRIAGES.}

BEACH-HADWEN.-On September 16th, at the Parish Church, Lancaster by the Rev. Canon Beach, M.A., Rector of North Fambridge, Essex, brother of the bridegroon, assisted by the Rev. J. I. Lewis, M. A., and the Rev. R. D. Bruce, B.A., Fletcher Beach, M.B., F.R.C.P.Lond., Emily Dora, second daughter of the late Henry Hadwen, Esq., of Ashfield, Lüncaster.

CLAYTON-Rowland. - On September 10th, at St. James's Church, Acerington, by the Rev. John Rogers, M.A., Vicar of the parish, assisted by the Rev. J. P. Petty, M.A.. James Simpson Clayton, M.B., C.M.Edin., eldest son of the late Richard Clayton, M.R.C.S., L.R.C.P., Ewbank,
Accrington, to Miranda (Minnie), only daughter of R. H. Rowland, Accrington, to Miranda (Minnie),
Esq., J.P., The Bank, Accrington.

Milnes-D'HAvet.-Hey Charles Edward Milnes, of Leeds, to Adeline, daughter of the Marchese D'Havet (Zuccardi).

PORTER-Browne.-On September 9 th, at St. Michael's, Wood Green, by the Rev. J. Thomas, M.A., Vicar. William Ernest Porter, M.B., D.P.H.Camb., of Ingress Housc, Trinity Road, Wood Green, and son
of William Porter, Goole, Yorkshire, to Eleanor Mary, elder daughter of T. Coster Browne, of the Limes, Wood Green.

Peirce-Bullivant.- On September 9 th, at St. James's, Shirley, by the Rev. C. Burd, M.A., Vicar of the parish, assisted by the Rev. D. D. Peirce, M.A., Vicar of Sarn, brother of the bridegroom, James E. Peirce, J.P. Surgeon, Newlands, Redditch, to Bertha, second da
of the late Joseph Bullivant, Esq., Shirley, near Birmingham.

\section{DEATHS.}

BASSETT.-On September 8th, at Steytlerville, near Uitenhage, Cape Colony, Henry Thurstan Bassett, M.B.Lond., late of Birmingham, aged 33 .

BROADBENT.-On September 16ith, at South Collingham, Notts, in her 66th year, Catharine, the wife of John Broadbent. No cards.

TAYLOR. - September 14th, at Torquay, Herbert Coupland Taylor, M.D., J.P., of Todmorden Hall, Lancashire, and Quinta Rochedo, Madeira son of the late James Taylor, of Todmorden Hall, Lancashire, and Culverlands, Berkshire, J.P., aged 36. Requiescat in Pace.

Vores.-On September 15th, at Ealing, William Vores, M.D., late of Great Yarmouth, aged 79 years.

Williams.-September 14th, at Sherborne, Dorset, William Henry Wil-
HOURS OF ATTENDANCE AND OPERATION DAYS AT THE LONDON HOSPITALS.

Caxcer, Brompton (Free). Hours of Attendance.-Daily. 2. Operation Days.-Tu. S., 2.

Central London Ophthalmic. Operation Days.-Daily, 2.

CHARING Cross. Hours of Attendance.-Medical and Surgical, daily, 1.30 ; Obstetric, Tu. F., 1.30; Skin, M., 1.30 ; Dental, M. W. F., 9; Throat and Ear, F., 9.30. Operation Days.-W. Th. F., 3.

Chelsea Hospital for Women. Hours of Attendance.-Daily, 1.30 . Operation Lays.-M. Th., 2.30.

EAST London Hospital FOR CHILDREN. Operation Day.-F., 2.

Great NorthenN Central. Hours of Attendance-Medical and Surgical, M. Tu. W. Th. F.,2.30; Obstetric, W, $2: 30$; Eye, Tu. Th., 2.30 ; Ear, M. F., 2.30: Diseases of the Skin, W., 2.30; Diseases of the 2 .

Gox s. Hours of Attendance.-Medical and Surgical, daily, 1.30 ; Obstetric, M. Tu. F., 1.30: Eje, M. Tu. Th. F., 1.30; Ear, Tu., 1; Skin, Tu. 1: Dentai, daily, 4: rhiroat. F., 1. Operation Days.-(Ophthalmic), M. Th., 1.30; Tu. F., l.30.

Hospital for Women, Solho. Hours of Attendance.-Daily, 10. Operation Days.-M. Thi., 2.

KING'S Corlege. Hour's of Attendance.-Medical, daily, 2 ; Surgical, daily, 1.30 ; Obstetric, daily, 1.30 ; o.p., Tu. W. F. S., 1.30 ; Eye, M. Th., 1.30 ; Throat, F., 1.30; Dental, Tu. Th., 9.30. Operation Days.Tu. F. S., 2 .

London. Hours of Attendance.-Medical, daily, exc. S., 2 ; Surgical, daily,

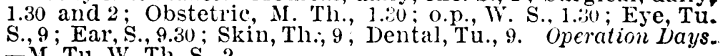

London TEMPERANCE HoSpital. Hours of Attendance-Medical, M. Tu. F., 2 ; Surgical, M. Th., 2 . Operai ion Days.-M. Th., 4.30.

Metropolitan. Inours of Attendance.-Nedical and Surgical, daily, 9 ; Obstetric, IV., 2. Operation Day.-F., 9.

Middesex. Hours of Attendance.-Medical and Surgical, daily, 1.30 ; Obstetric, M. Th., 1.30 ; o.p., M. F., 9, W., 1.30 ; Eye, Tu. F., 9 ? Ear and Throat, Tr., 9 ; Slin, Tu., 4, Th., 9.31 ; Dental, M. 'W" F., 9.30. Operation Days.-W., 1, S., 2 ; (Obstetrical), W., 2.

National ORThopadic. Hours of Attendance.-M. Tu. Th. F., 2. Operation Day. - W., 10.

North-West London." Hours of Attendance. - Medical and Surgical, daily, 2 ; Obstetric, W., 2 ; Eye, W., 9; Skin, Tu., 2 ; Dental,
F., 9. Operation Day.-Th., 2.30 .

ROYAL Free. Hours of Attendance. - Medical and Surgical, daily, 2 ; Diseases of Women, Tu. S., $9 ;$ Eye, M. F., 9 ; Dental, Th.. 9. Operation Days.-W. S., 2 ; (Ophthalmic), M. F., 10.30 ; (Diseases

Royal London OpHThalmic. Hours of Attendance.-Daily, 9. Operation

Days.-Daily, 10 .
ROYAL ORTHOPADIC. Hours of Attendance.-Daily, 1. Operation Day.-

Royal Westirinster OpHThalmic. Hours of Attenciance. - Daily, 1. Operation Days.-Daily.

ST. BARTHoLOMEw's. Hours of Attendance.-Medical and Surgical, daily, 1.30 ; Obstetric, Tu. Th. S., 2 ; o.p., W. S., 9 ; Eye, W. Th. S.; 2.30 ; Ear, Tu. F., 2 ; Skin, F., 1.30; Larynx, F., 2.30; Orthopadic, M., 2.30 ; Dental, Tu. F., 9.

ST. George's. Hours of Attendance.-Medical and Surgical, M. Tu. F. S., 12 ; Obstetric, Th., 2 ; o.p., Eye, W. S., 2 ; Ear, Tu., 2 ; Skin, w., 2 ; Throat, Th., 2 ; Orthopædic, w.. 2 ; Dental, Tu. S., 9 . Operation Days.-Th., 1; (Ophthalmic), F., 1.15 .

ST. Mark's. Hours of Attendance.-Fistula and Diseases of the Rectum, males, W., 8.45; females, Th., 8.45 . Operation Day.-Tu., 2.

St. Mary's. Hours of Attendance.-Medical and Surgical, daily, 1.45; o.p. 1.30 ; Obstetric, Tu. F., 1.45; Eye, Tu. F. S.,9; Ear, M. Th., $3 \%$ Orthopædic, W., 10 ; Throat, Tu. F., 1.20 ; Skin, M. Th., 9.30 ; Electro-therapeutics, Tu. F., 2 ; Denta], W. S., 4.30; Consultations, M., 2.30. Operation Days.-Tu., 1.30; (Orthopadic), W., 11; (Oplithalmic), F., 9.

ST. PEter's. Hours of Attendance.-M., 2 and 5 , Tu., 2, W., 2.30 and 5 , Th.,

ST. THomas's. Hours of Attendance.-Medical and Surgical, daily, exc. W. and S., 2 ; Obstetric, Tu. F., 2; o.p., W. S., 1.30: Eye. Tu., 2 o.p., daily, exe S., 1.30; Ear, M. 1.30; Skin, F., i.:30; Throat, Days.-W. S., 1.30 ; (Ophthalmic), Tu., 4, F., 2 ; (Gynacological) Th., 2 .

SAMARITAN FREE For WOMEN AND CHILDREN. Hours of Attcndance.Daily, 1.30. Operation Day. - IV., 2.30.

TirroAt, Golden Square. Hours of Attendarce.-Daily, 1.30; Tu. and F., 6.30 ; Operation Day. Th., 2 .

Cniversity College. Hours of Attendance-Medical and Surgical. dally, 1.30 ; Obstetrics, M. W. F.. 1.30; Eye, M. Th., 2; Ear, 11. Th.. 9 Skin, W., 1.45, S. 9.15; Throat, M. Th., 9; Dental, W., 9.30 Operation Days.-iw. Th., $1.30 ;$ S., 2.

West Londow. Hours of Attendance.-Medical and Surgical, dally, 2 Dental, Tu. F., 9.30; Eye. Tu. Th. S., 2 ; Ear, Tu., 10 ; Orthopædic: W., 2 ; Diseases of Women, W. S., 2 ; Electric, Tu., 10, F., 4 ; Skin, F, 2 ; Throat and Nose, S., 10. Operaticil Days.-Tu. F., 2.30 .

Fiestanster. Houre of Atier,ience.-Medical and surgical, dally, $1 ; \mathrm{Ob}$. stetric, Tu. F., 1 : Eve, M. Th. 2.30; Ear, M., 9; Ekin, W., 1;
Dental, W. S., 9.1. 